Article

\title{
Time-Series Analysis on Persistent Scatter-Interferometric Synthetic Aperture Radar (PS-InSAR) Derived Displacements of the Hong Kong-Zhuhai-Macao Bridge (HZMB) from Sentinel-1A Observations
}

\author{
Siting Xiong ${ }^{1,2} \mathbb{D}$, Chisheng Wang ${ }^{1,3, *}$, Xiaoqiong Qin ${ }^{1,3}$, Bochen Zhang ${ }^{1,2}$ and Qingquan Li $^{1,2}$ \\ 1 Ministry of Natural Resources (MNR) Key Laboratory for Geo-Environmental Monitoring of Great Bay Area \\ \& Guangdong Key Laboratory of Urban Informatics \& Shenzhen Key Laboratory of Spatial Smart Sensing \\ and Services, Shenzhen University, Shenzhen 518060, China; xiongsiting@szu.edu.cn (S.X.); \\ xqqin@szu.edu.cn (X.Q.); zhangbc@szu.edu.cn (B.Z.); liqq@szu.edu.cn (Q.L.) \\ 2 College of Civil and Transportation Engineering, Shenzhen University, Shenzhen 518060, China \\ 3 School of Architecture \& Urban Planning, Shenzhen University, Shenzhen 518060, China \\ * Correspondence: wangchisheng@szu.edu.cn
}

Citation: Xiong, S.; Wang, C.; Qin, X.; Zhang, B.; Li, Q. Time-Series Analysis on Persistent Scatter-Interferometric Synthetic Aperture Radar (PS-InSAR) Derived Displacements of the Hong Kong-Zhuhai-Macao Bridge (HZMB) from Sentinel-1A Observations.

Remote Sens. 2021, 13, 546.

https://doi.org/10.3390/rs13040546

Academic Editor: Diego Di Martire

Received: 8 January 2021

Accepted: 29 January 2021

Published: 3 February 2021

Publisher's Note: MDPI stays neutral with regard to jurisdictional claims in published maps and institutional affiliations.

Copyright: ( $\odot 2021$ by the authors. Licensee MDPI, Basel, Switzerland. This article is an open access article distributed under the terms and conditions of the Creative Commons Attribution (CC BY) license (https:// creativecommons.org/licenses/by/ $4.0 /)$.

\begin{abstract}
The synthetic aperture radar interferometry (InSAR) technique has been applied in monitoring the deformation of infrastructures, such as bridges, highways, railways and subways. Persistent scatterer (PS)-InSAR is one of the InSAR techniques, which utilises persistent scatterers to derive longterm displacements. This study applied time-series methods to post-process the PS-InSAR-derived time-series displacements with the use of 86 Sentinel-1A acquisitions spanning from 6 January 2018 to 27 November 2020. Empirical mode decomposition (EMD) and seasonal and trend decomposition using loess (STL) were combined to estimate the seasonal component of the total time-series displacements. Then, a temperature correlation map was generated by correlating the seasonal component with the temperature variation. Results show that the thermal expansion phenomenon is pronounced on the buildings of the Zhuhai-Macao Passenger Terminal as well as the bridge and road connecting to the Hong Kong International Airport (HKIA), while it is less obviously observed at the main Hong Kong-Zhuhai-Macao Bridge (HZMB). In addition, sudden changes between subsidence and uplift can be detected through the $p$-values derived by applying the augmented Dickey-Fuller (ADF) test to the residual signals after removing the linear and seasonal components from the original ones.
\end{abstract}

Keywords: interferometric SAR; time-series analysis; thermal expansion; bridge monitoring

\section{Introduction}

Monitoring the deformation of bridges is vital for ensuring the safety of cities and humans. Deformation of bridges can be dangerous when it is caused by unhealthy structure. Apart from the reliable but labour-intensive way of visual inspection, advanced on-site and remote monitoring techniques have been proposed for this application [1]. On-site surveys involve the usage of infrared thermography and spectroscopy [2], laser scanning [3], ground-penetrating radar [4], GPS receivers [5], etc. These sensors or instruments can be set up on bridges; however, the point-wise measurements have a low spatial sampling rate when not enough sensors are employed. Remote monitoring techniques include ground-based radars [3,6], airborne cameras/lidar [7] and spaceborne synthetic aperture radars (SARs) [8]. The ground-based radar is expensive, and it is often hard to configure at a fixed location to collect continuous observations. Airborne cameras/lidar are not applicable on cloudy days, and routine flights are usually at a higher expense. The SAR interferometry (InSAR) technique has been developed for more than three decades, and it can be used to obtain terrain movement over a large area in a short time. Therefore, InSAR, especially multi-temporal (MT)-InSAR [9-11], has been proposed for long-term 
deformation monitoring of bridges in several previous studies [12-22], and meanwhile, this application is greatly benefited from the large volume of datasets from satellites, such as Envisat, Sentinel-1, COSMO-SkyMed and TerraSAR.

In the field of infrastructure monitoring, the spaceborne InSAR technique has been gaining more and more popularity [12-26]; it has been reported to be applicable and effective in monitoring bridges more than once. For instance, Sousa and Basto reported that a deformation rate of about $20 \mathrm{~mm} /$ year had occurred before the collapse of a bridge in Italy, demonstrating the potential of MT-InSAR techniques for deformation detection in bridges [12]. Milillo et al. applied persistent scatterer (PS)-InSAR analysis to the Envisat data spanning 2003-2011, the COSMO-SkyMed and the Sentinel-1A/B spanning 2009-2018 [13]. Their results reveal that the Morandi Bridge in Genoa, Italy, had been undergoing an increased magnitude of deformations prior to its collapse on 14 August 2018.

Thermal expansion of the infrastructures can be observed in the InSAR results, which have been reported by many previous studies $[17-20,23,26]$. For example, this phenomenon was noticed in displacements of the Rainbow Bridge and Lupu Bridge in Tianjin, as well as a highway bridge in Hebei, China [18-20]. A linear model based on a priori knowledge of temperature change was applied to separate phase caused by thermal expansion in [18]. In $[19,20]$, the thermal expansion was visually observed in interferograms and unwrapped phase and then quantitatively estimated by considering temperature and bridge structure. However, when it comes to InSAR results of a large area, different targets in the scene may react differently to the same temperature variation. Therefore, a method to detect where the thermal expansion occurs, and where abrupt or hazardous changes of the displacements are, is needed, especially when there is not enough priori knowledge.

InSAR-derived displacements are basically time-series signals; however, few studies involve the topic of how to apply time-series analysis methods to deal with the thermal expansion. Actually, in the field of time-series analysis, data representation can be used to reduce the dimensions and extract representative features of the time-series signals. For example, Zhu et al. used a combination of a piecewise linear model and a sinusoidal model for estimating the non-linear and periodic components in the displacements [27]. This is an example of importing time-series analysis into post-processing of InSAR-derived displacements. It is based on the assumption that the periodic variation follows a sinusoidal model which may be impractical for some targets, and it needs an input parameter of partition numbers for the piecewise linear model. To improve this, we proposed the usage of empirical mode decomposition (EMD), seasonal and trend decomposition using loess (STL) and augmented Dickey-Fuller (ADF) test to analyse the InSAR-derived displacements. The EMD and STL are used to decompose a seasonal component from the original displacements, which does not involve any presumption models. After removing the linear and seasonal component, the ADF test is applied to the residual, and time-series with sudden changes can be identified. The study area, data and methods are introduced in Section 2. In Section 3, we present the results of PS-InSAR displacements and their post-processing analysis. Finally, several key points are discussed and concluded in Sections 4 and 5.

\section{Materials and Methods}

\subsection{Study Area}

Starting from a man-made island (IS4) east of Hong Kong International Airport (HKIA), the Hong Kong-Zhuhai-Macao Bridge (HZMB) crosses Pearl River Estuary (PRE) and connects to the man-made island in Zhuhai and Macao (IS1) as shown in Figure 1. The green dots in Figure 1 show locations of two meteorologic stations, one in the HKIA and the other in the Macao International Airport (MIA). The study area is located in the subtropical region, which receives sufficient solar heat and rainfall. It is warm and humid in the summer, while dry in the winter. The annual mean temperature in the PRE is about 21.4-22.4 ${ }^{\circ} \mathrm{C}$, and it is a bit higher in the study area. The annual mean precipitation is 1600-2300 mm, most of which is between April and September. 


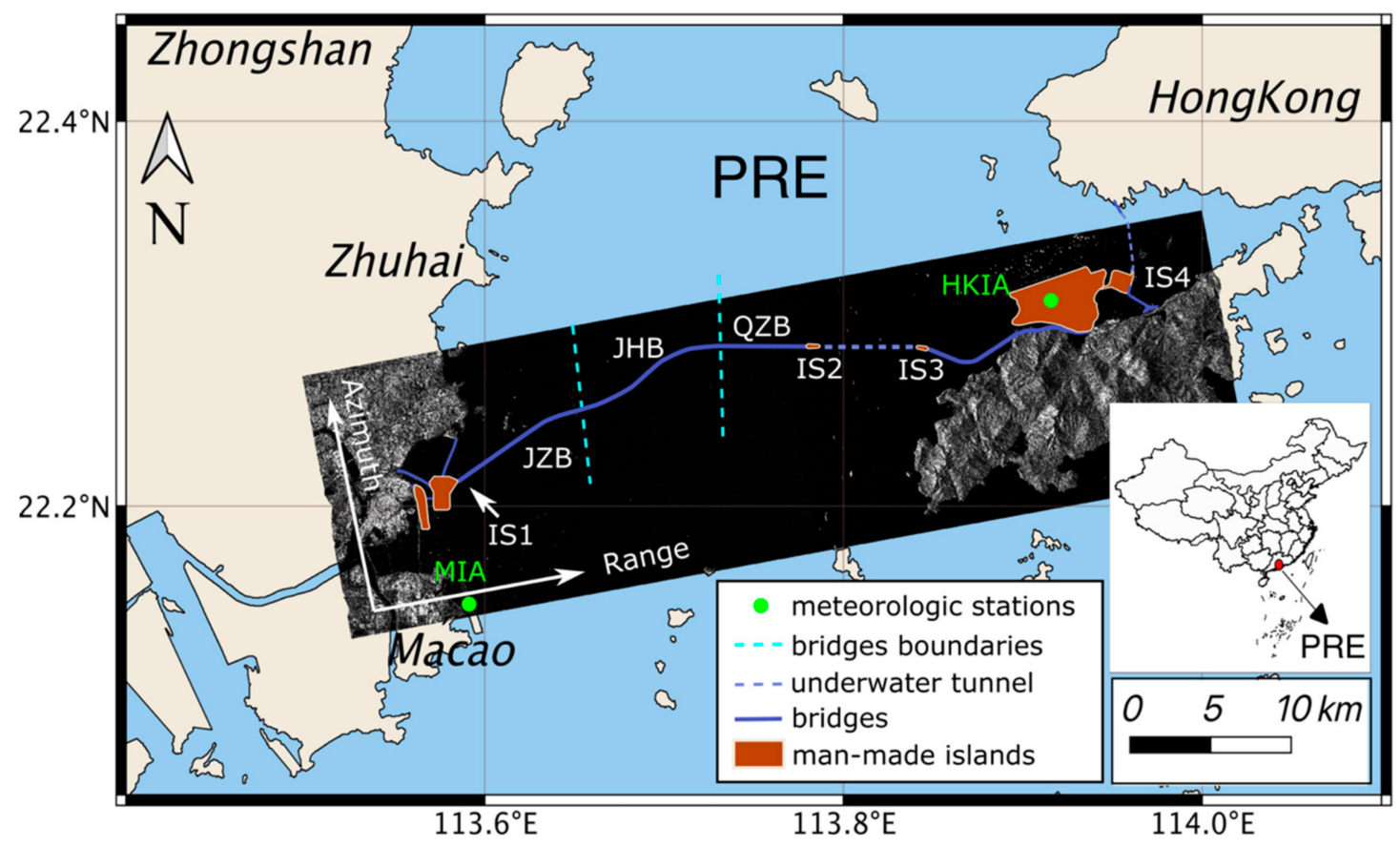

Figure 1. The study area of the Hong Kong-Zhuhai-Macao Bridge (HZMB), consisting of Jiuzhou Bridge (JZB), Jianghai Bridge (JHB) and Qingzhou Bridge (QZB), is located at the Pearl River Estuary (PRE) as indicated in the inset. The western segment of the HZMB is connected with the eastern segment via one underwater tunnel between the western (IS2) and eastern (IS3) man-made islands. (IS1: reclaimed island for the Zhuhai-Macao Passenger Terminals, and IS4: reclaimed island for the Hong Kong Passenger Terminal). The two green dots show the location of two meteorologic stations in the Hong Kong International Airport (HKIA) and Macao International Airport (MIA). The background image is an intensity image of the Sentinel-1A acquisition on 30 May 2018.

The main bridge of HZMB comprises three channel bridges, namely Jiuzhou Bridge (JZB), Jianghai Bridge (JHB) and Qingzhou bridge (QZB) from west to east, allowing ship travel, and blocked bridges in-between these three channel bridges. The cyan dotted lines indicate the separation of the three cable-stayed bridges. In addition, the main bridge is connected to an underwater tunnel of $6 \mathrm{~km}$ via the west man-made island (IS2) and is connected to the Hong Kong Bridge (HKB) via the east man-made island (IS3) [28]. The whole length is $55 \mathrm{~km}$, including the main bridge of $29.6 \mathrm{~km}$ [29].

Construction of the HZMB started on 15 December 2009 and was completed on 7 July 2017. The average depth of water in this region is about $37 \mathrm{~m}$ and is up to $44 \mathrm{~m}$ at some points on man-made islands. Construction of man-made islands was first to remove clays on the sea bottom and then to employ many concrete cylinders on the solid sea base (61 cylinders for west and 59 for the east). Twisted $\mathrm{H}$-shaped concrete constructs are floating around the man-made islands to protect them from sea waves. The sea bottom was excavated as a bowl shape, and the tunnel was built on it. Later, the tunnel was buried by gravels and clays. This means the tunnel is sticking to the sea bottom apart from transitions near the islands.

\subsection{PS-InSAR Processing Based on GAMMA and Stanford Method for Persistent Scatterers (StaMPS)}

In this study, we collected 86 Sentinel-1A acquisitions in the Interferometric Wide (IW) mode spanning from 6 January 2018 to 27 November 2020. This dataset is processed using the PS technique with the use of GAMMA [30] and StaMPS [31]. InSAR processing, including swath and burst selection, co-registration, image cropping and interferogram formation, are carried out with the usage of GAMMA. The PS processing, including PS selection and unwrapping, is realised by using StaMPS software. StaMPS uses different temporal and spatial characteristics to estimate the atmospheric and orbital phases. The whole processing flow is listed in Figure 2. Since there is only one ascending orbit covering 
the HZMB and no enough temporal coverage of other SAR datasets, such as TerraSAR and Cosmo-SkyMed datasets, cross-validation cannot be achieved. The following analysis is based on the line of sight (LOS) displacements due to the single geometry available.

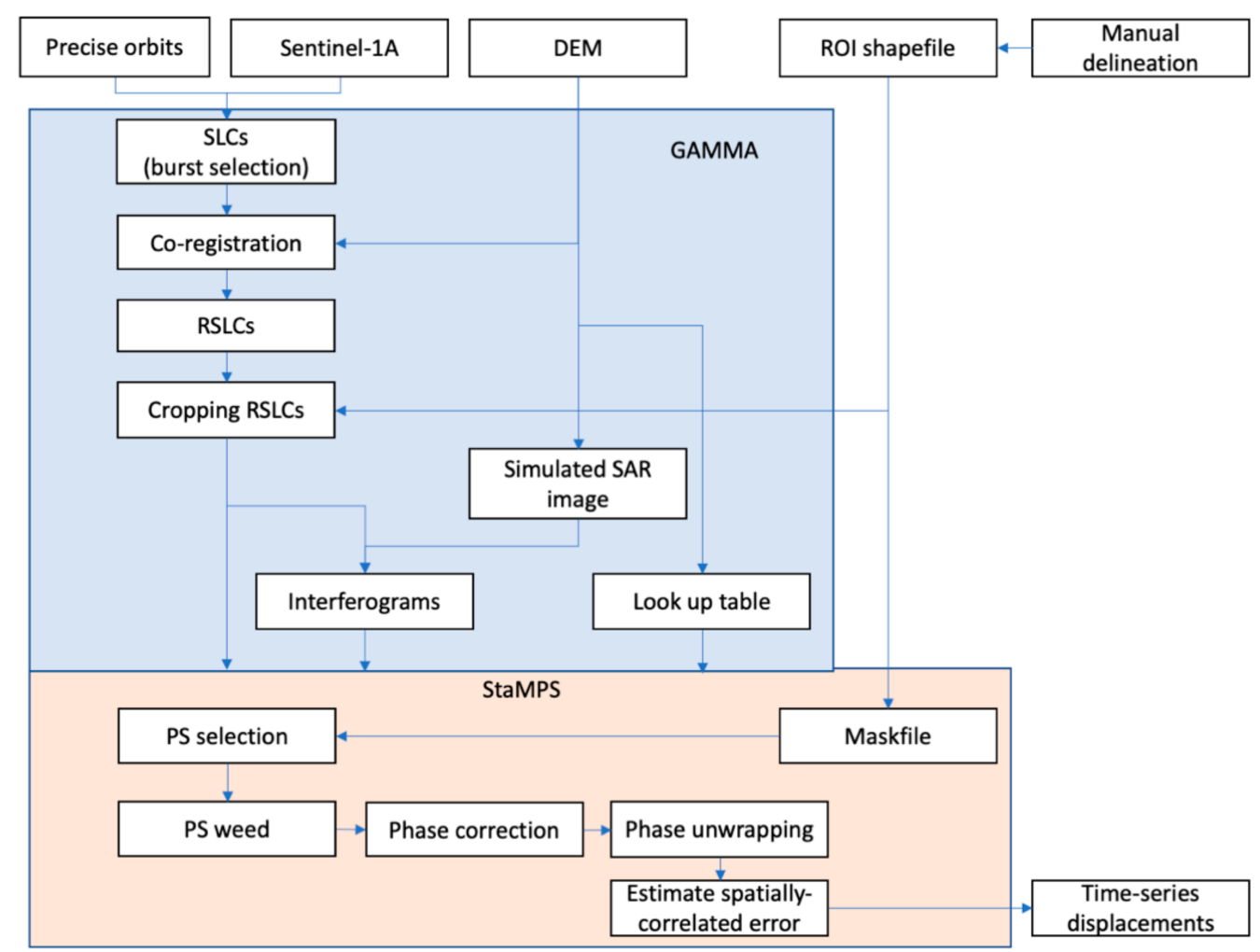

Figure 2. The processing flow of a persistent scatter-interferometric synthetic aperture radar (PS-InSAR).

One phenomenon in PS selection is that some strong scatterers near the sea area have strong side lobes, causing false selections in the sea area as shown in Figure $3 b, c, e$. Figure $3 b$ shows that a strong scatterer occurred in the acquisition on 6 May 2018, and since then, it became a persistent scatter. Figure $3 \mathrm{c}$ shows persistent scatterers with side lobes on the JHB, which may be caused by the cable towers on the bridge. Figure 3 e presents a dominant scatterer in the HKIA which may shadow the neighbouring targets. Apart from these, some other noises are also selected in the sea area, which may be caused by speckle noises as shown in Figure 3d. StaMPS selects the initial PS candidates with the amplitude dispersion and filters the selection afterwards with the phase noise characteristics. However, it cannot exclude the false selections as shown in Figure 3d,e. Therefore, in this study, a mask of the sea area is applied to the initial PS candidates.

The side lobe effect is found to be less pronounced in the VH than in the VV polarisation. However, an obvious seam line is found between the swaths 2 and 3 of $\mathrm{VH}$ polarisation, as seen in Figure 4a, while it cannot be observed in VV polarisation shown in Figure $4 \mathrm{~b}$. Apart from this difference, the number of PS targets selected in VV polarisation is about twice more than that in $\mathrm{VH}$ polarisation. It is about 127,532 for $\mathrm{VH}$ polarisation and about 225,993 for VV polarisation. Most of the targets, which are not selected in $\mathrm{VH}$ polarisation, are located on the roads, bridges and buildings. Considering these differences, we finally choose the VV polarisation. 


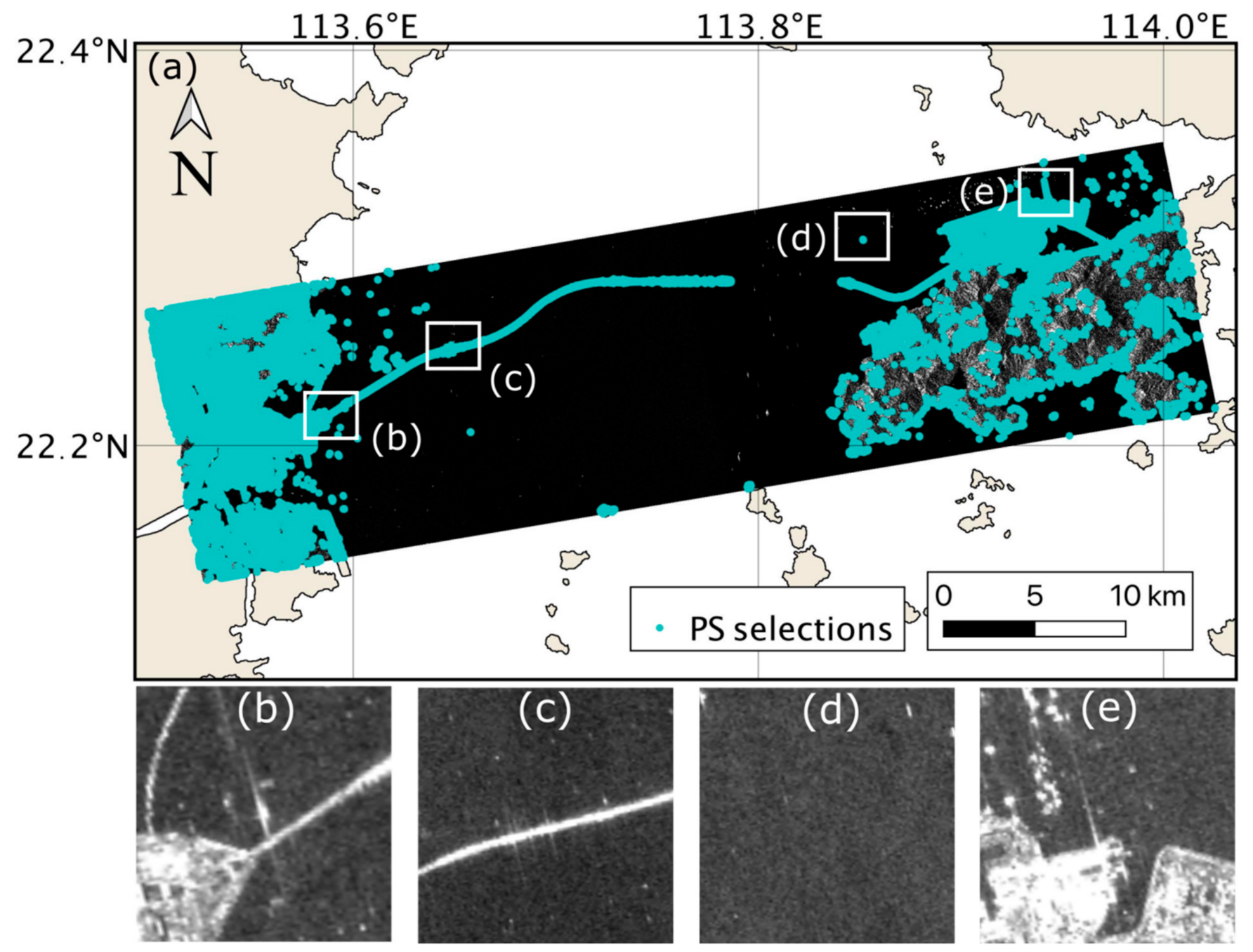

Figure 3. (a) PS selections denoted as blue points; $(\mathbf{b}-\mathbf{e})$ are subsets of the multiple look $(10 \times 2$ looks $)$ image on 10 October 2020, among which (b) is one permanent scatter that has occurred since acquisition on 6 May 2018, with long tails along the azimuth direction; (c) is one segment near the JHB showing strong permanent scatters; (d) is one example of false selection affected by speckle noise; (e) is one permanent scatter with a long tail. The tail along the azimuth direction shown in $(\mathbf{b}, \mathbf{c}, \mathbf{e})$ is caused by a strong side lobe effect.

\subsection{Post-Processing Based on Time-Series Analysis}

The final product derived from PS processing is the long time-series displacements of the selected PS targets. After the PS processing, major parts of the phase errors should be removed, while a small amount of noise can still remain. Conventionally, the linear displacement rate is what we use to detect whether there is a subsiding area or uplift area. With the usage of the linear rate, the residual noise is of not much impact as it can be considered as white noise.

However, apart from the linear rate, the intrinsic displacement variation can tell us more information. For example, it tells us whether there is a seasonal or periodic component, or whether it contains an abrupt change. Therefore, we propose to apply a post-processing flow to decompose these components. The processing steps are listed in Figure 5 and are described in the following sections. For each PS target, there is an original InSAR-derived time-series displacements, denoted as $\mathbf{x}_{0}(\mathrm{t})$, where $t$ is the acquisition dates. The post-processing starts from $\mathbf{x}_{0}(\mathbf{t})$ as seen in Figure 5. 

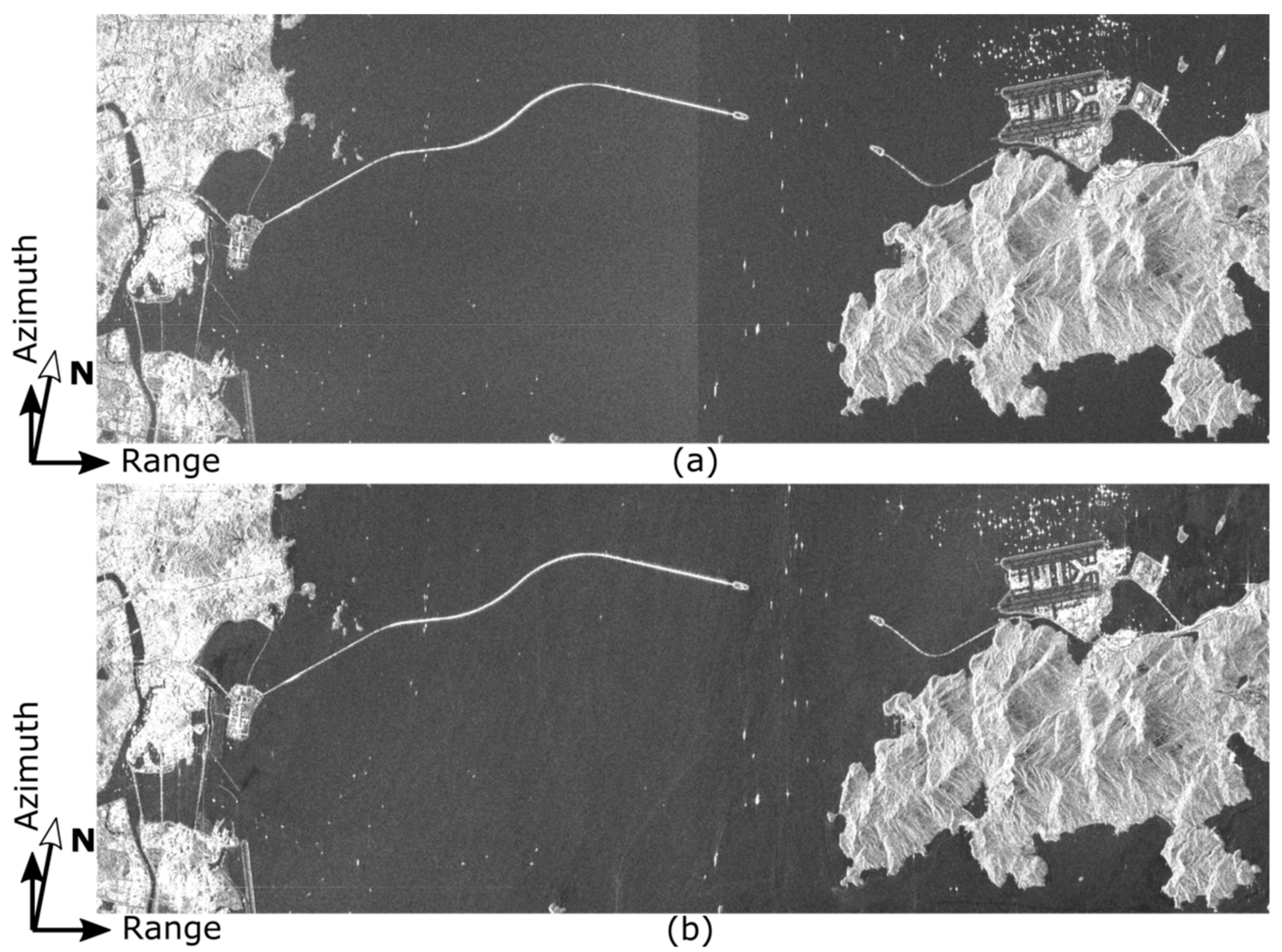

Figure 4. Amplitude images of (a) VH and (b) VV polarisations acquired on 30 May 2018 in the radar imaging geometry.

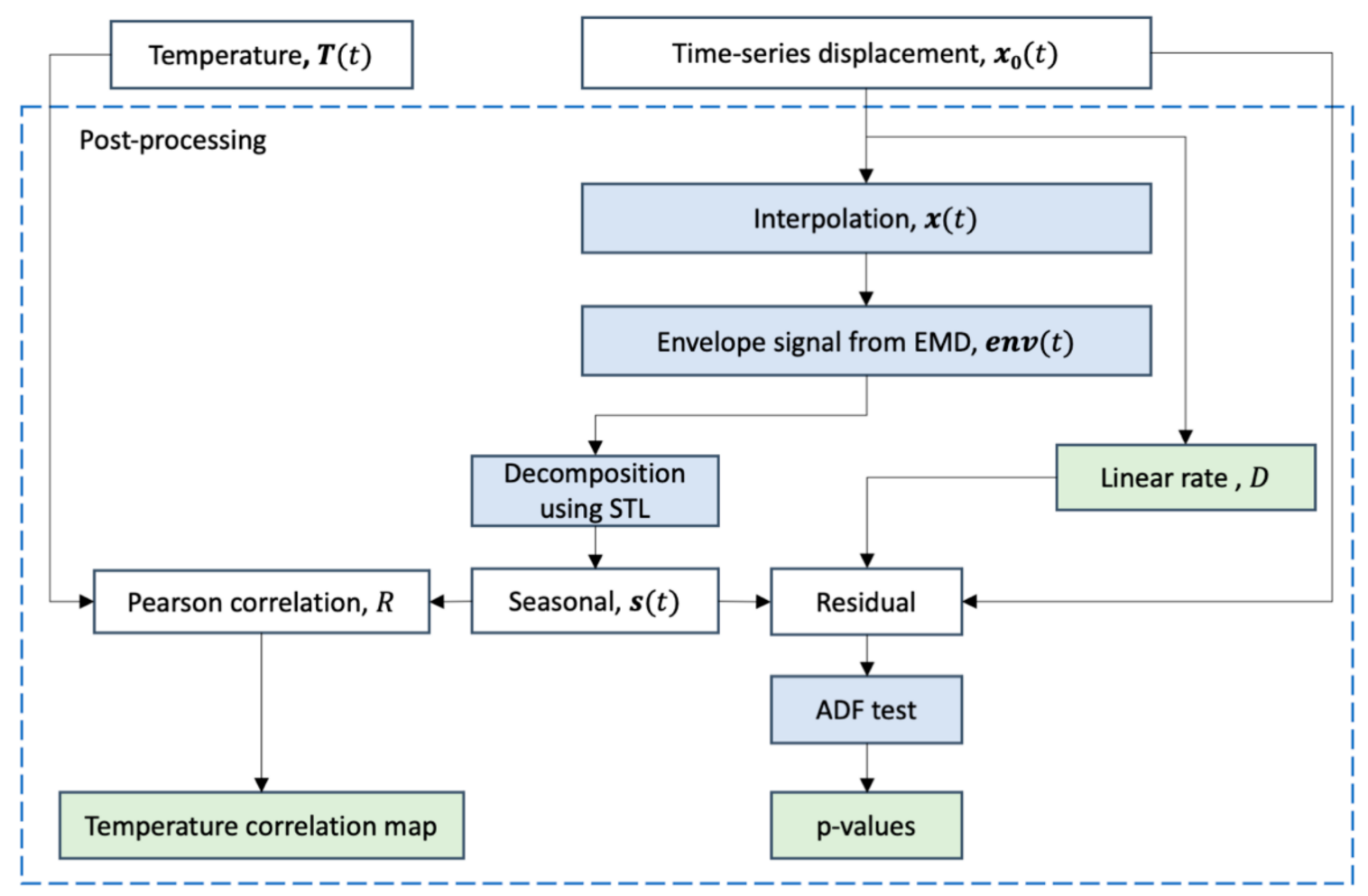

Figure 5. The flowchart of post-processing steps on the InSAR-derived displacements. 


\subsubsection{Interpolation and Linear Fit}

With the InSAR-derived time-series displacements, the linear rate is estimated by using the first polynomial fitting. As a result, we obtain a linear rate, D, as shown in Figure 5. Although spaceborne SAR images are usually acquired at a regular revisit time (12 days for Sentinel-1A), there might be missing acquisitions, leading to an irregular temporal sampling rate. In this case, there is no acquisition on 18 January 2018, 25 May 2019 and 19 May 2020. Therefore, we used linear interpolation to resample the time-series signals to a rate of 12 days. This time-series signal is denoted as $\mathbf{x}(\mathbf{t})$, where $t=\{1,2,3, \ldots, N\}$, and $\mathrm{N}$ is the number of acquisitions at a regular period of 12 days.

\subsubsection{Temperature Correlation Based on EMD and STL}

In this section, the EMD and STL decomposition are combined to decompose the seasonal variation from the original displacements. In the EMD algorithm, the local minimums and maximums of the signal are selected and fitted by using spline interpolation, forming an upper and a lower envelop, which are denoted as $\operatorname{emax}(t)$ and $\operatorname{emin}(t)$, respectively. Then, the first intrinsic mode function (IMF) is generated by subtracting the mean envelop between upper and lower ones from the original signal [32]. This process is iterated until the IMF is monotonic, and the generated IMFs, $\mathbf{c}_{\mathrm{i}}(\mathrm{t})$, can be added up to restore the original signal as in Equation (2).

$$
\begin{gathered}
\mathbf{c}_{\mathrm{i}}(\mathrm{t})=\mathbf{c}_{\mathrm{i}-1}(\mathrm{t})-\mathbf{e n v}_{\mathrm{i}-1}(\mathrm{t})=\mathbf{c}_{\mathrm{i}-1}(\mathrm{t})-\frac{\operatorname{emax}_{\mathrm{i}-1}(\mathrm{t})+\mathbf{e m i n}_{\mathrm{i}-1}(\mathrm{t})}{2} \\
\mathbf{x}(\mathrm{t})=\sum_{\mathrm{i}=1}^{\mathrm{n}} \mathbf{c}_{\mathrm{i}}(\mathrm{t})+\operatorname{res}_{\mathrm{n}}(\mathrm{t})
\end{gathered}
$$

where $\mathrm{N}$ is the total number of IMFs, and $\operatorname{res}_{\mathrm{n}}(\mathrm{t})$ is the residual component from EMD.

From the above deduction, we can see that mean envelop can be a good representative of the original InSAR-derived displacements as it contains the main characteristics of the original signal while excluding primary noises. Therefore, the STL decomposition is applied to the mean envelop to derive the seasonal components, which are denoted as $\mathbf{s}(\mathbf{t})$ [33]. This seasonal component is what we infer to be correlated with the temperature variation. It should be noted that the STL decomposition needs an input of period. Considering the air temperature change has a cycle of one year, this input parameter is set to be 30 samples in this case as the 12 days revisit time of the Sentinel-1A dataset.

For different targets, the decomposed seasonal component may or may not be correlated to air temperature variation. To evaluate their correlation, we calculated a Pearson correlation coefficient, $\mathrm{R}$, between the seasonal component, $\mathbf{s}(\mathrm{t})$, and an a priori temperature variation, $T(t)$. The temperature records of the two meteorologic stations in the HKIA and MIA are collected from the Global Surface Summary of the Day (GSOD) product, which is released by the National Oceanic and Atmospheric Administration (NOAA) [34]. In addition, we also collect the precipitation records to assist the post-analysis. These two types of data are extracted according to the dates of Sentinel-1A acquisitions. The air temperatures and precipitations with regards to the acquisition dates are shown in Figure 6. The rainfall season in 2018 was delayed for about two months compared with that between April and September in 2019 and 2020.

\subsubsection{Irregular Variation Detected by ADF Test}

Time-series signals can be principally classified into stationary and non-stationary. The stationary time-series manifests no obvious periodic and trend variation, while the non-stationary one contains trend or periodic signals. ADF test is a unit root test for stationarity $[35,36]$. The null hypothesis for this test is that there is a unit root. ADF test outputs a p-value which indicates the probability that you can reject the null hypothesis. Generally, a $p$-value of less than 5\% means you can reject the null hypothesis, which means the time series is stationary. In this study, we calculate the $p$-values of each PS time-series displacements after subtracting the linear trend and the seasonal variation. We examine 
whether these $p$-values can help to detect which targets suffer from the sudden changes of displacements.

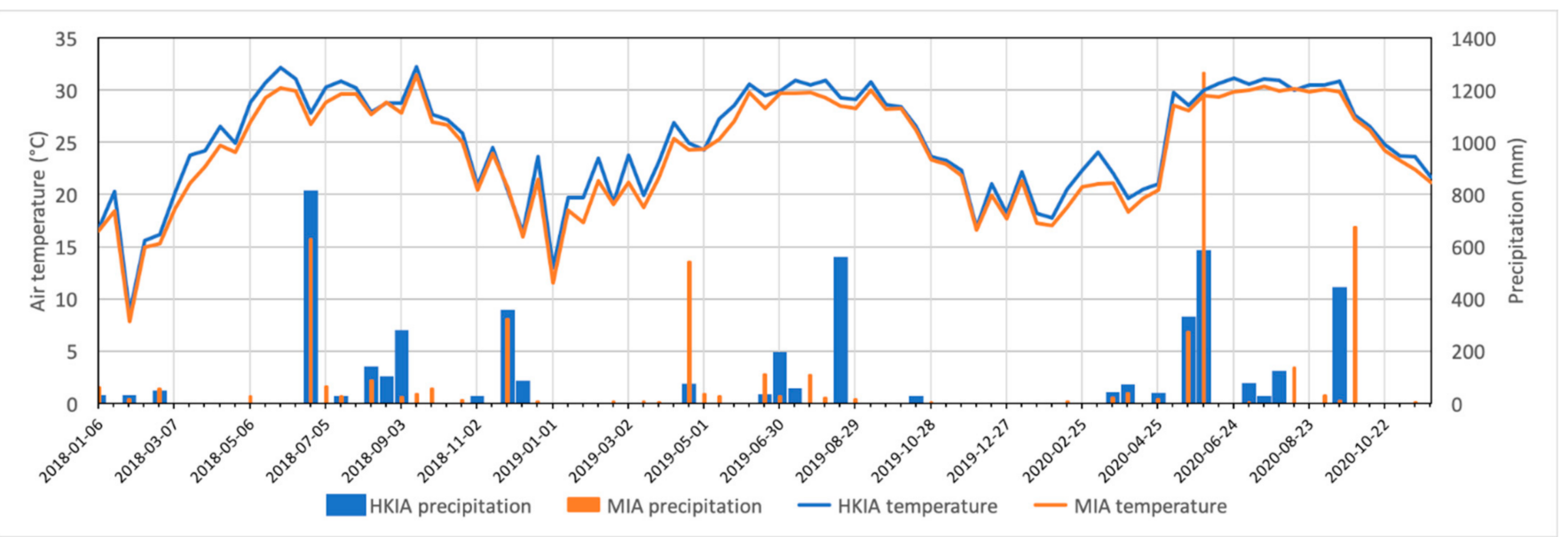

Figure 6. Air temperatures and precipitations on the acquisition dates of two meteorologic stations in the HKIA and the MIA.

\section{Results}

\subsection{InSAR-Derived Time-Series Displacements}

The linear displacement rate along the LOS direction and its standard deviation are shown in Figure 7a,b. The positive displacement rate indicates the targets moving towards the satellite along the LOS direction, while the negative values moving far away. One close-up shows the main HZMB as demonstrated in Figure 8. Close-ups of the white boxes in Figure 7a are demonstrated in Figure 9. As we can see, one sudden change of the standard deviation occurs at the west end of the QZB as indicated by the red box (the right one) in Figure $7 \mathrm{~b}$. This can be the cause of the difference in the standard deviation between the west and east parts of the scene. The location of the sudden change is about $5 \mathrm{~km}$ from the boundary between swaths 2 and 3, which is annotated as a red dashed line in Figure $7 \mathrm{~b}$. Since the StaMPS carries out unwrapping with the construction of Delaunay Triangles, triangles related to the east part of the QZB segment have long sides connecting to the main land. This may lead to an unwrapping error occurring at this place, which is propagated to the east of the scene. As InSAR results are relative measurements, relative movements are still valid in the results. It is very suggestive to have stable GPS receivers installed in the west and east man-made islands for correcting the PS-InSAR derived displacements. Unfortunately, in this study, we had no corrections for this.

Figure 8 demonstrates the displacement rate map of the main HZMB. Figure $8 \mathrm{~b}-\mathrm{d}$ are three close-ups showing displacements of the JZB, the JHB and the QZB, respectively. As we can see that the displacements rate of most targets is ranging between -2 to $+2 \mathrm{~mm} /$ year across these three bridges. Two exceptions are one bridge segment east of the JHB suffering from a larger uplift of 2 4 mm/year and one segment west of the QZB suffering a subsidence larger than $2 \mathrm{~mm}$ /year, as indicated by the red boxes. These two regions are correspondent to the areas indicated by red boxes in Figure 7b. Apart from these regions, the peripheral IS2 is subsiding at a rate of $2 \sim 4 \mathrm{~mm} /$ year. Compared to the periphery of the man-made island, the main bridge is relatively stable. Figure $8 \mathrm{~b}$ shows that spans of the JZB have a subsidence of $0 \sim 2 \mathrm{~mm}$ /year, while Figure $8 \mathrm{c}$ shows the JHB is more stable. Figure $8 \mathrm{~d}$ shows a typical deformation pattern of the cable-stayed bridge and that the middle of the span has larger deformation than the two towers. 

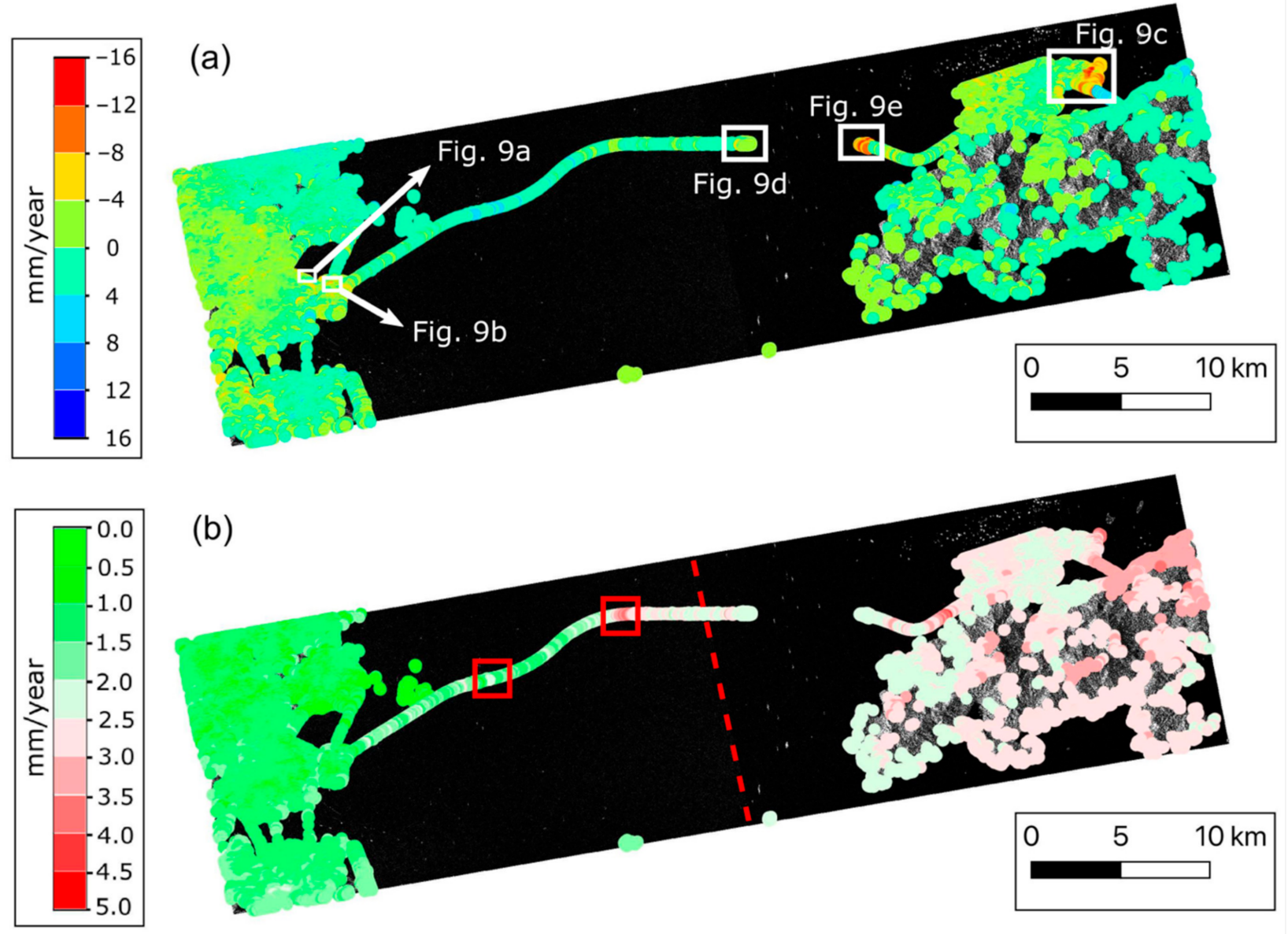

Figure 7. PS-InSAR results of the HZMB bridge: (a) the displacement velocity, regions in the white boxes are enlarged in Figure $9 \mathrm{a}-\mathrm{e}$; (b) the standard deviation map of regression. The red boxes indicate the abnormal changes, and the red dashed line is the boundary between swath 2 and swath 3 .

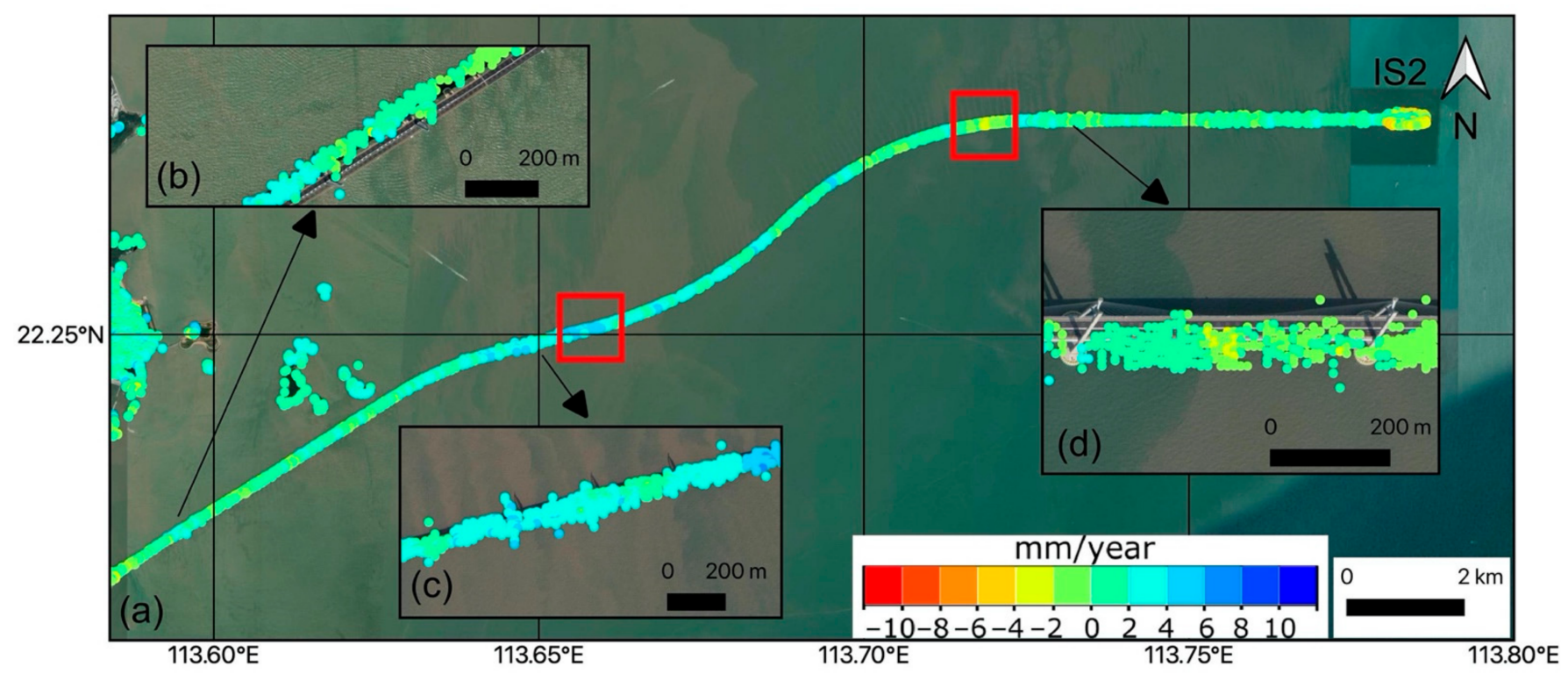

Figure 8. The close-up shows displacements of (a) the main HZMB and three bridges: (b) JZB, (c) JHB and (d) QZB. The background is the satellite image from Google Earth. 


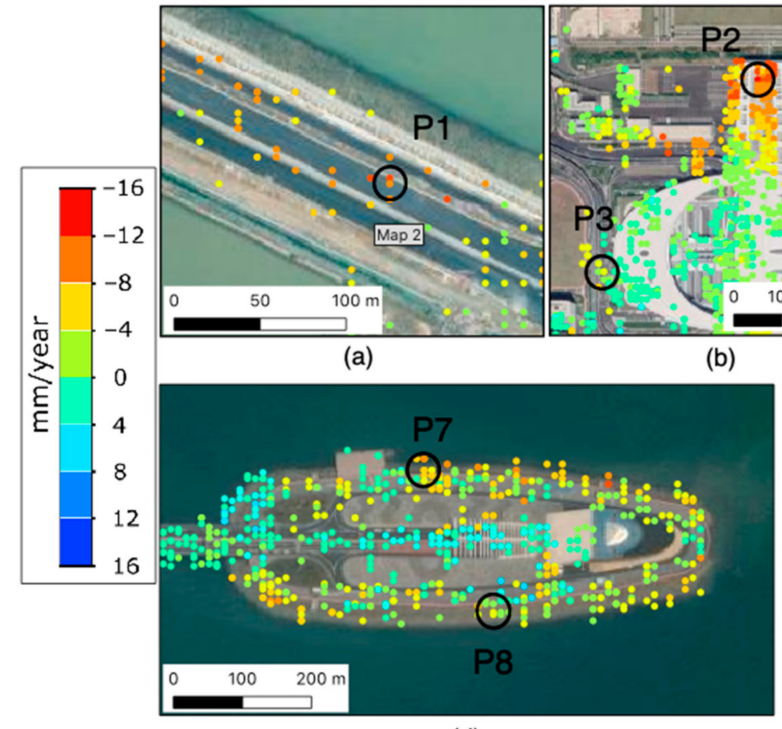

(d)

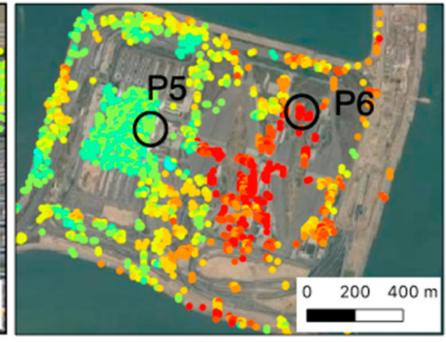

(c)

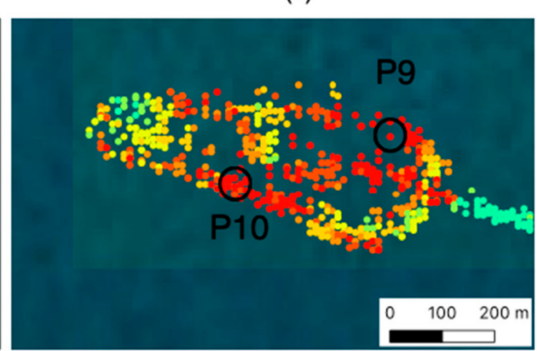

(e)

Figure 9. Close-ups of (a) a part of the bridge connecting Zhuhai city and the Zhuhai Passenger Terminal; (b) northern part of the Zhuhai Passenger Terminal; (c) the IS4; (d) the IS2; and (e) IS3. The background is the satellite image from Google Earth. P1-P10 are ten examples which are listed in Table 1 and discussed in Section 3.2.

Table 1. Latitudes and Longitudes of P1-P10 shown in Figure 9. The P3 and P4 are of a correlation coefficient above 0.6 and lower than -0.6 , respectively.

\begin{tabular}{|c|c|c|c|c|c|c|}
\hline Label & No. & $\begin{array}{l}\text { Latitude } \\
\text { (Degree) }\end{array}$ & $\begin{array}{l}\text { Longitude } \\
\text { (Degree) }\end{array}$ & $\begin{array}{l}\text { Linear rate } \\
\text { (mm/Year) }\end{array}$ & $\mathbf{R}$ & Description \\
\hline P1 & 130840 & 113.5612 & 22.2150 & -7.6953 & -0.4585 & Bridge from Zhuhai city to Zhuhai Terminal \\
\hline $\mathrm{P} 2$ & 146143 & 113.5759 & 22.2107 & -10.7019 & -0.1649 & Northern cloister of Zhuhai Passenger Terminal \\
\hline P3 & 152783 & 113.5730 & 22.2071 & -0.6469 & 0.6580 & Back of the Zhuhai Passenger Terminal \\
\hline $\mathrm{P} 4$ & 154301 & 113.5773 & 22.2074 & -3.4231 & -0.8345 & Front of the Zhuhai Passenger Terminal \\
\hline P5 & 75982 & 113.9519 & 22.3180 & 0.1343 & -0.3382 & East side of the Hong Kong Terminal \\
\hline P6 & 77437 & 113.9577 & 22.3186 & -13.3084 & -0.3245 & A small building \\
\hline P7 & 74556 & 113.7829 & 22.2841 & -5.3813 & 0.1513 & North of the west man-made island \\
\hline P8 & 80161 & 113.7838 & 22.2822 & -1.8265 & 0.0781 & South of the west man-made island \\
\hline P9 & 110165 & 113.8458 & 22.2826 & -11.2244 & 0.3566 & Northeast of the east man-made island \\
\hline P10 & 111034 & 113.8432 & 22.2817 & -13.5703 & 0.0177 & South of the east man-made island \\
\hline
\end{tabular}

Figure 9a shows that the road bridge connecting Zhuhai city and the Passenger Terminal is suffering a subsidence of $4 \sim 8 \mathrm{~mm} /$ year. Figure $9 \mathrm{~b}$ shows that the northern cloister of the Zhuhai Passenger Terminal (located on the IS1) is subsiding at a yearly rate of $4 \sim 12 \mathrm{~mm}$, while its east side is subsiding at a yearly rate of $0 \sim 4 \mathrm{~mm}$. Figure 9c demonstrates an uneven subsidence of targets on the IS4. Some targets on the eastern part are subsiding at a rate of $8 \sim 16 \mathrm{~mm} /$ year, but the main building on the island located on the west side appears to be stable. Figure $9 \mathrm{~d}$ shows the displacements of targets on IS2. It can be seen that the peripheral of the IS2 has a slight subsidence rate of $4 \sim 8 \mathrm{~mm} /$ year, while the middle part is quite stable. Meanwhile, Figure $9 \mathrm{~d}$ shows that the IS3 suffers a relatively larger subsidence rate, which ranges from $12 \sim 16 \mathrm{~mm} /$ year. This subsidence mainly occurs at the northeastern and southern peripheries of the island. What is more, a subsidence rate of $12 \sim 18 \mathrm{~mm} /$ year can also be observed at the east end of the central road on the island. We select several PS targets, P1-P10, as examples and present their decomposed seasonal variations in Figures 10-13. Their locations and descriptions are listed in Table 1. 


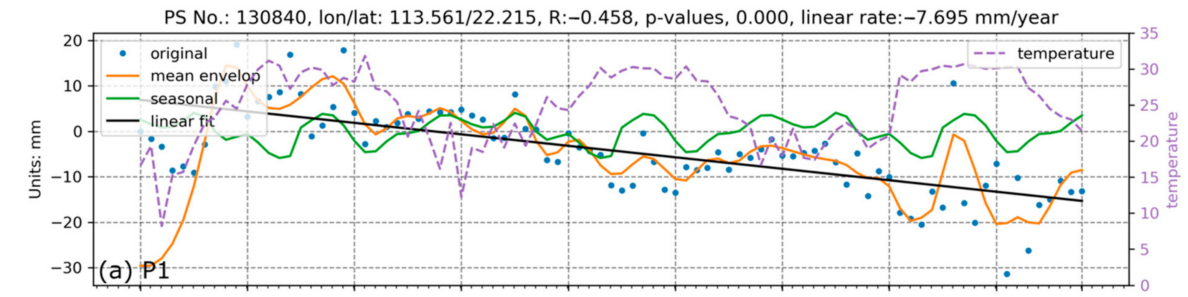

PS No.: 146143, Ion/lat: 113.576/22.211, R:-0.165, p-values, 0.000, linear rate:-10.702 mm/year
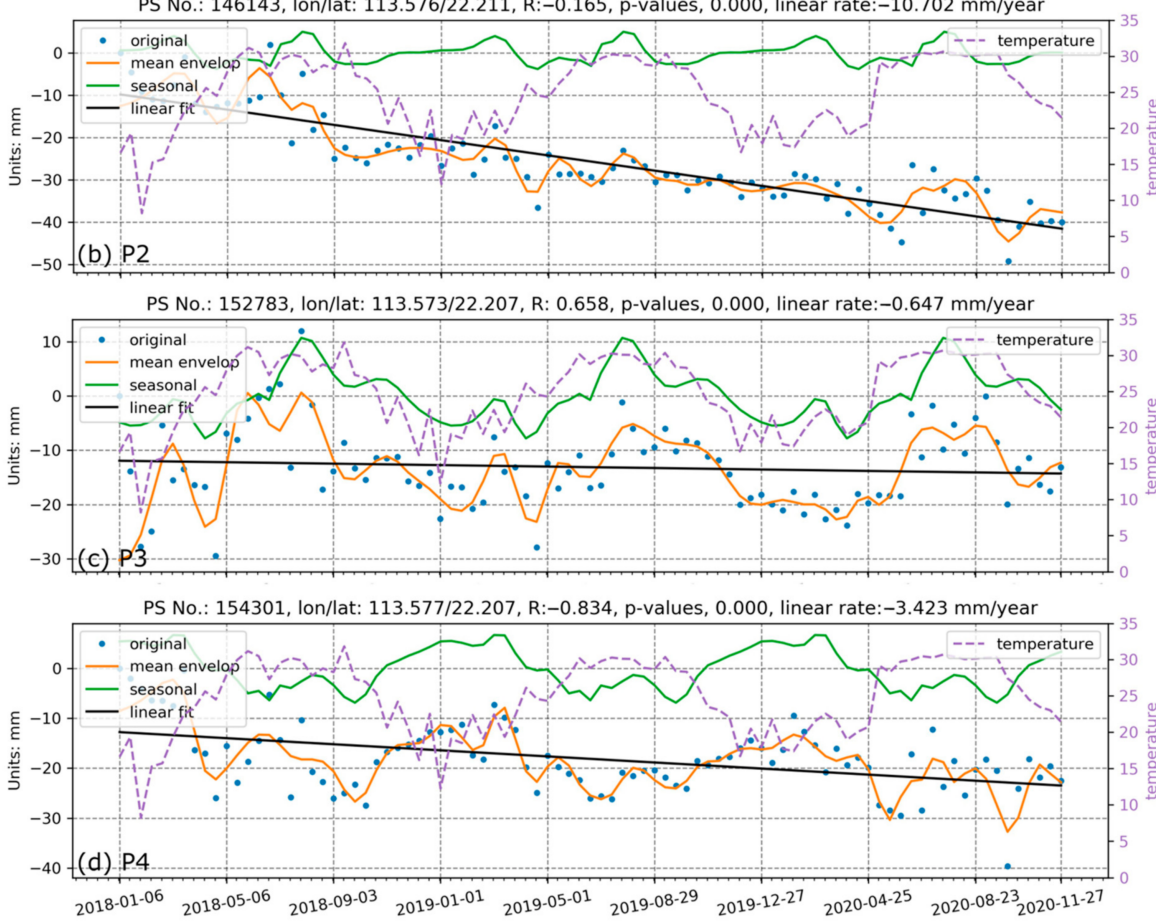

Figure 10. Time-series processing results of (a) P1 located on the bridge connecting Zhuhai city and Zhuhai Passenger Terminal, (b) P2 located on the northern cloister, (c,d) P3 and P4 located at the front and back of Zhuhai Passenger Terminal.
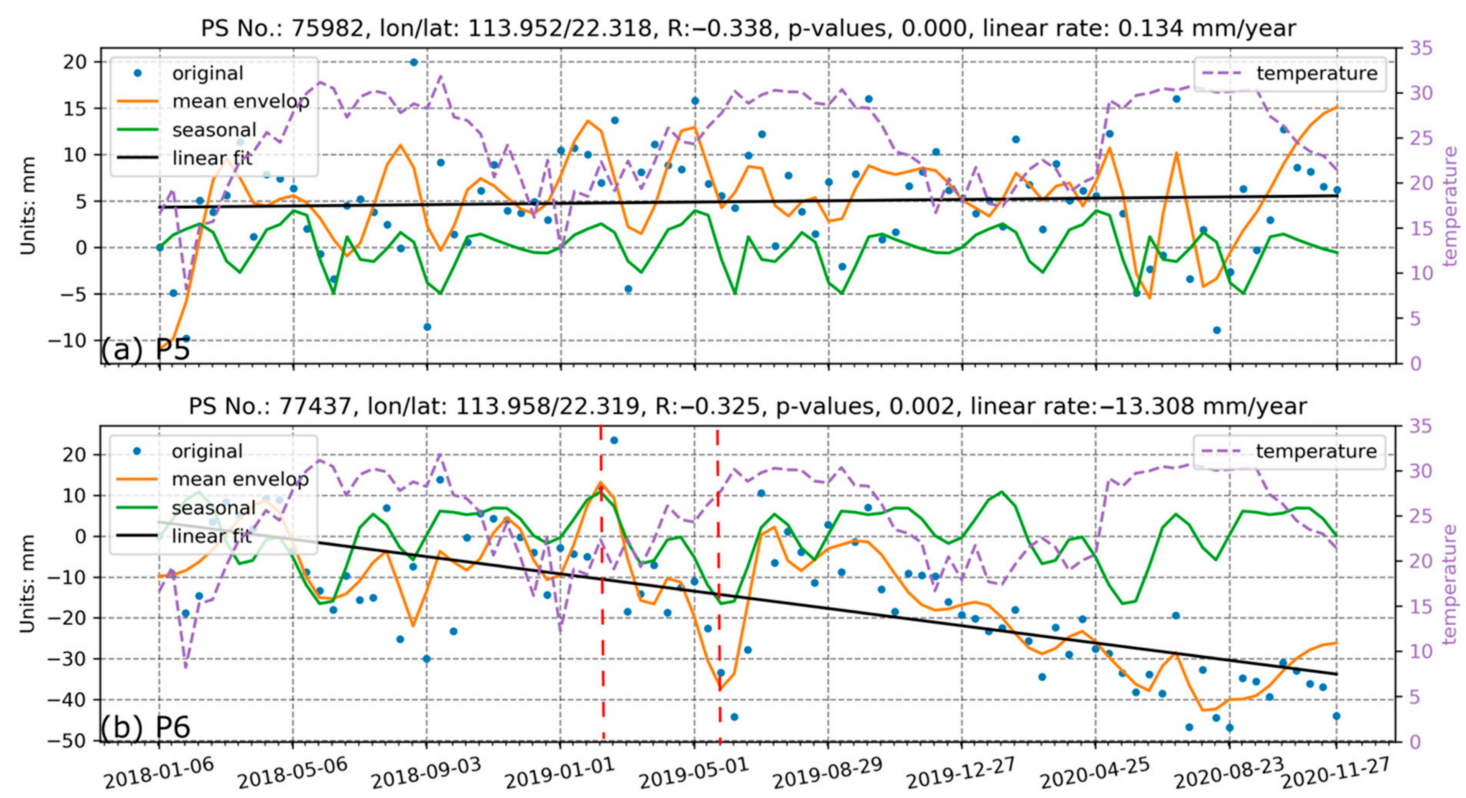

Figure 11. Time-series processing results of (a) P5 and (b) P6 on the Hong Kong Passenger Terminal. The red dashed lines indicate a period of a large subsidence. 

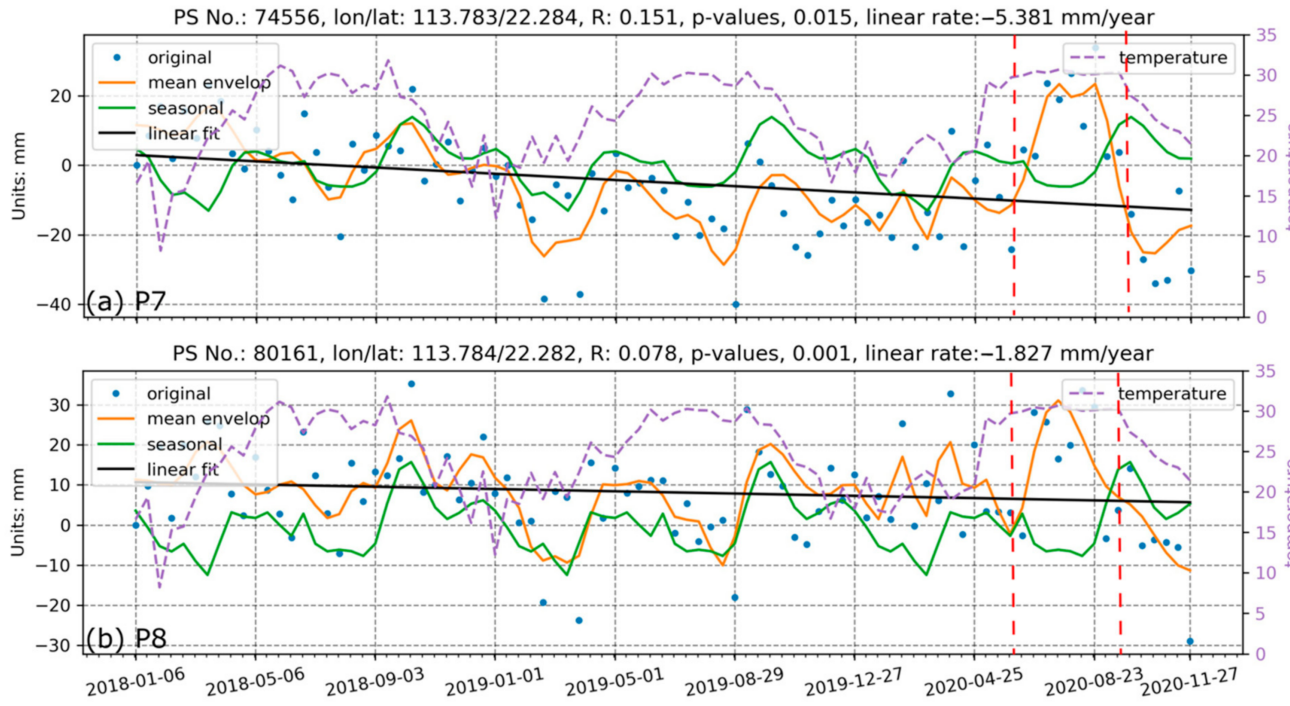

Figure 12. Time-series processing results of (a) P7 and (b) P8 at the north and south of the west man-made island. The red dashed lines indicate sudden uplifts on P7 and P8 between the middle of June and the middle of September in 2020.
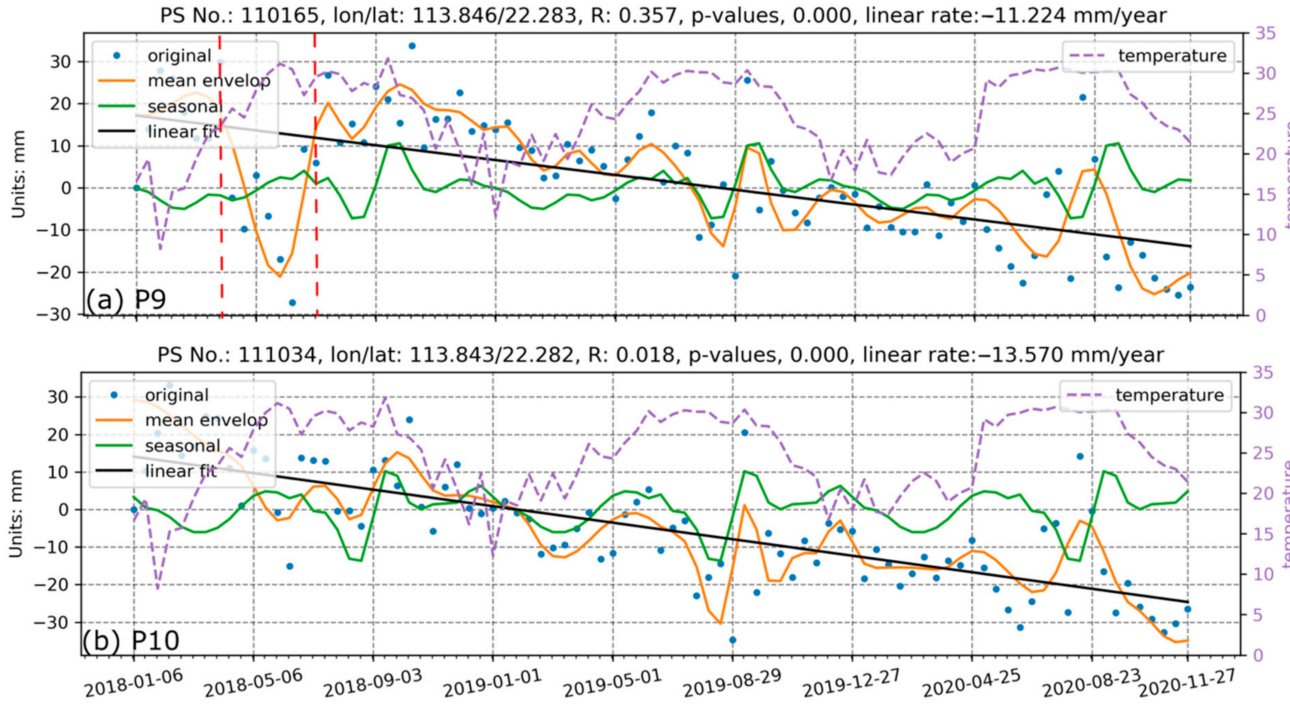

Figure 13. Time-series processing results of (a) P9 and (b) P10 at the northeast and south of the east man-made island. The red dashed lines indicate the period between April and June in 2018.

\subsection{Post-Processing Based on Time-Series Analysis}

The displacement variation of the PS targets, P1-P10, are shown in Figures 10-13. The blue dots are original InSAR displacements. The initial output of the StaMPS takes the master acquisition as the reference. We rectify it to be the date of the first acquisition, which is 6 January 2018. The seasonal component, which is denoted as green lines in Figures 10-13, is produced by using the algorithms shown in Figure 5. The mean envelop is denoted as orange lines. As seen in Figure 10, P1 is located at the road bridge connecting Zhuhai city and the Passenger Terminal. P2 is located at the northern cloister of the Zhuhai Passenger Terminal. Both P1 and P2 suffer a continuous subsidence without obvious periodic deformation. On the contrary, the decomposed seasonal change of P3 and P4 (as the green lines) appear to be highly positively and negatively correlated with the temperature variation (plotted as the purple lines), respectively. Their temperature correlation coefficient is -0.6580 and 0.8345 , respectively.

Figure 11 shows two targets on the man-made island for Hong Kong Passenger Terminal (IS4). These two targets present no obvious temperature correlation while they 
are not showing the same subsiding rate. The P5 is quite stable with a linear displacement rate of only $0.134 \mathrm{~mm}$ /year. However, the P6 is subsiding at a rate of $13.308 \mathrm{~mm} /$ year, and the red dashed lines in Figure $11 \mathrm{~b}$ show a period of a large displacement from early February to the end of May in 2019.

Targets P7 and P8 are located on the IS2, while P9 and P10 are located on the IS3. The temperature correlation is very low comparing the purple dashed line and the green line in Figures 12 and 13. However, it appears there is a cyclic pattern of half a year on P7 and P8 when observing the green lines. The red dashed lines in Figure 12 highlight large uplifts that occurred on P7 and P8 between the middle of June and the middle of September in 2020. Figure 13 shows that P9 and P10 have large subsiding rates. A large subsidence occurred on P9 between April and June in 2018 as shown by the red dashed lines in Figure 13a. We can see from the results that the seasonal component estimated by using the STL is more resistant to this sudden change.

The abovementioned targets are presented as examples. Actually, for every PS target, the decomposition of seasonal change and its correlation with temperature change are carried out. The correlation coefficient map of the whole scene is shown in Figure 14a. Figure $14 \mathrm{~b}$ shows that a positive correlation occurs on the west side of the building roof and the negative on the east side of the roof. On the other hand, the typical pattern of temperature correlation of the bridge segment connecting to Hong Kong is highlighted by the left white box in Figure 14c. Along this segment, there is a high frequent alternation between positive and neutral correlations. The right white box in Figure 14c shows a road segment on which a high frequent alternation between positive and negative correlations occurs. Different from the bridge and road segments, this high frequent alternative correlation is not obviously observed in the main HZMB.

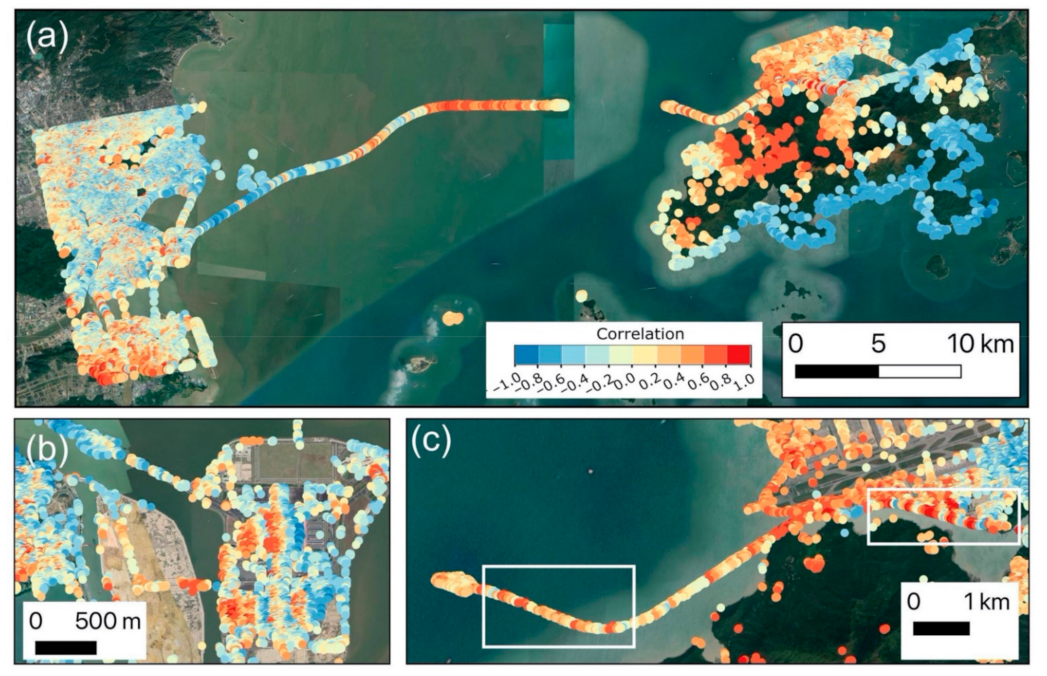

Figure 14. The correlation map between (a) temperature and the seasonal component of time-series displacements; (b) the cyclic correlation pattern of the buildings in the Zhuhai-Macao Passenger Terminals; (c) the white boxes show the cyclic correlation pattern of the bridge and road connecting the east man-made island and the HKIA. The background image is a satellite image from Google Earth.

The decomposed seasonal trend and linear trend were removed from the original time-series, and then we applied the ADF test to the residual signals. Figure 15 shows the $p$-values derived by the ADF test, in which the white dots show the stationary time-series. The stationarity of the time-series means that after removing the temperature correlated trend and linear trend, no apparent regular trend remains in the time-series, and the residual can be correspondent to white noise. On the contrary, the red dots with different scales (0.001-1) show the non-stationary time-series, which indicate there is still a regular or abnormal trend preserved in the time-series signals. We chose three examples and plotted the original signals and the residuals after removing linear and seasonal components in 
Figure 16. For point A1, which is located at the northern cloister of the Zhuhai Passenger Terminal, there is a jump of the time-series displacement around March 2020. This jump can also be observed at A2, which is located at the southeast of the Macao Passenger Terminal. For the point A3, a change from continuous subsidence to uplift occurs around August in 2019.

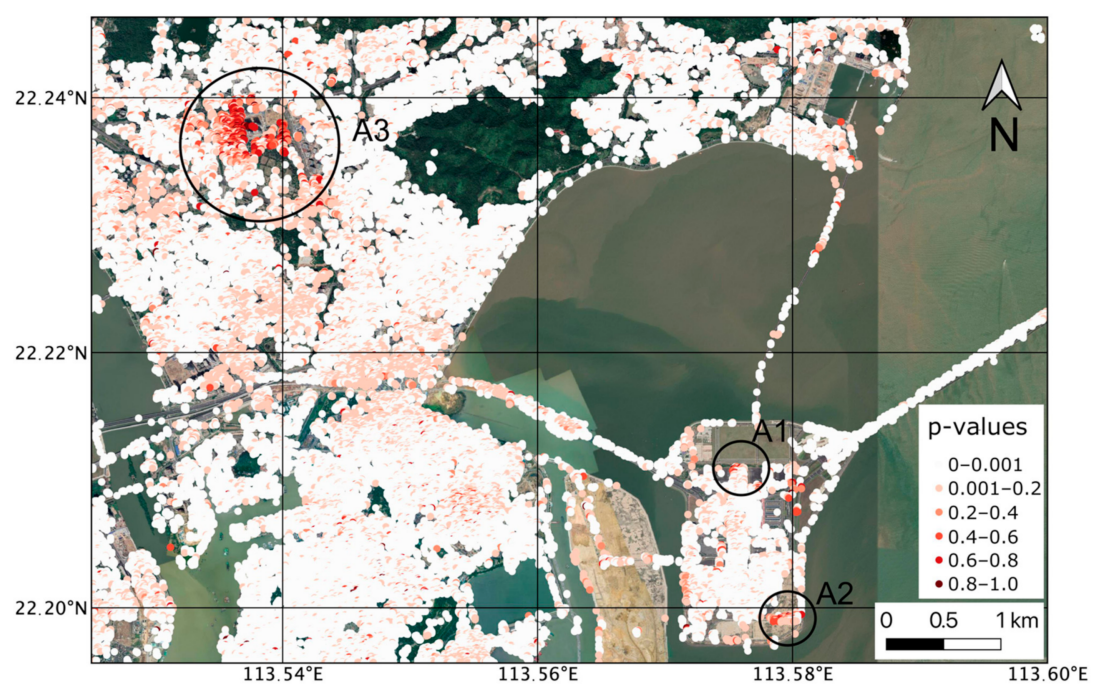

Figure 15. The $p$-values from the ADF test after removing the linear and seasonal components.

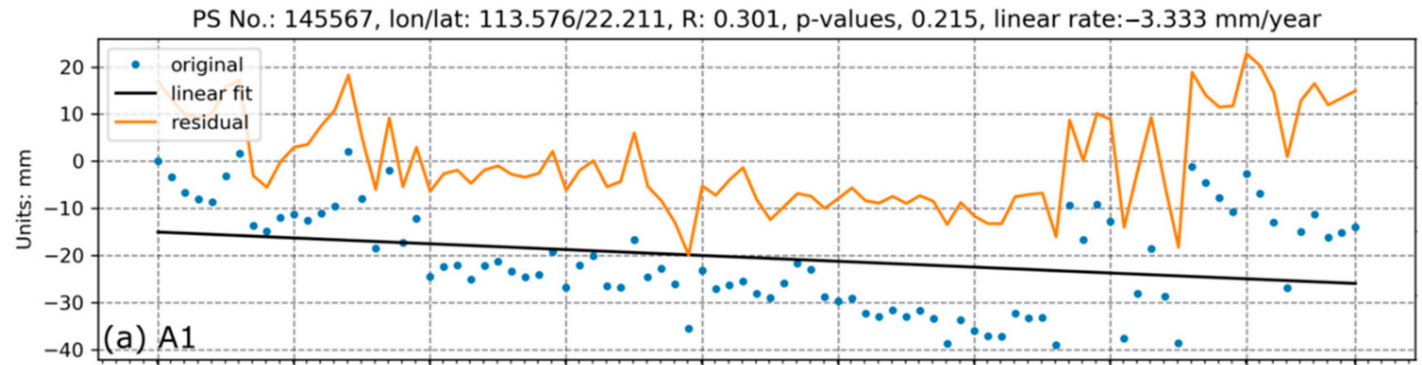

PS No.: 172685, Ion/lat: 113.579/22.199, R: 0.053, p-values, 0.474, linear rate: $0.109 \mathrm{~mm} /$ year

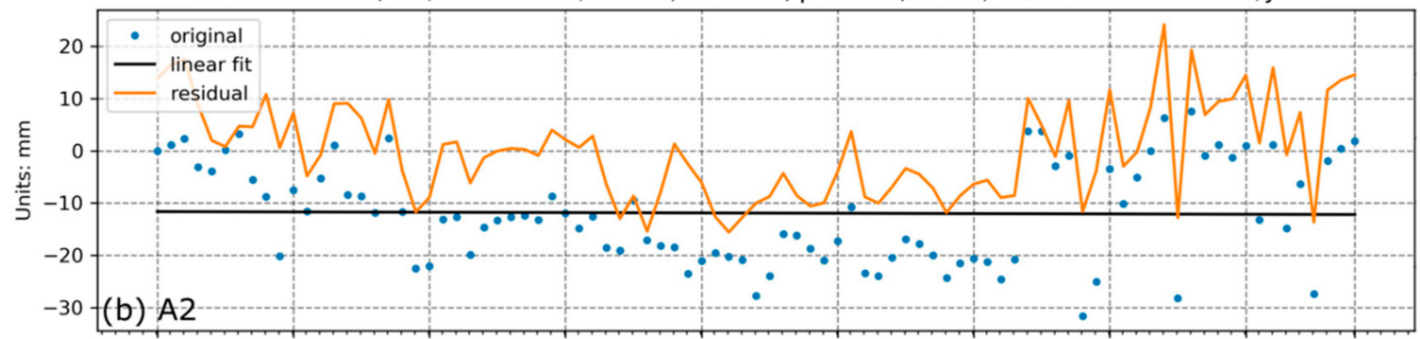

PS No.: 63582, Ion/lat: 113.540/22.238, R:-0.206, p-values, 0.786, linear rate:-1.850 mm/year

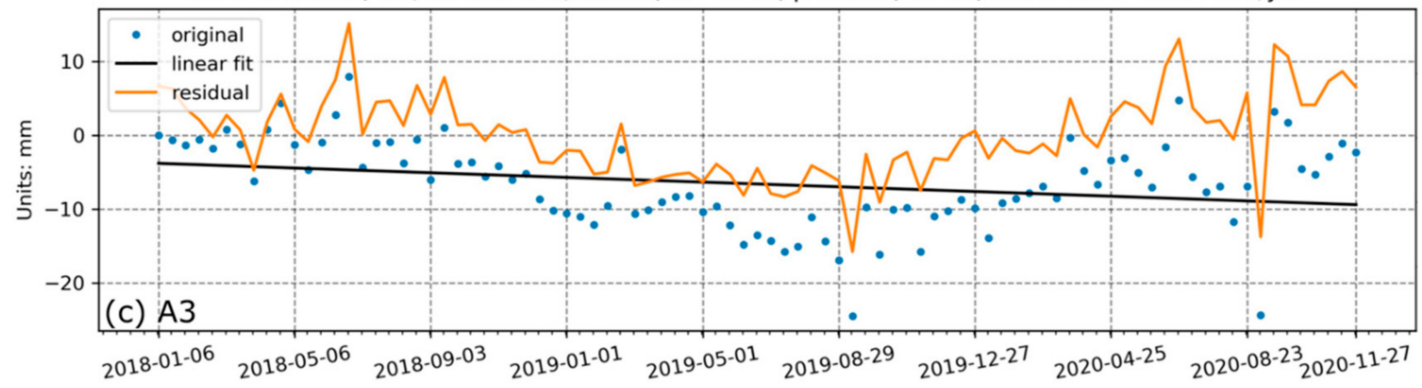

Figure 16. The displacement variation of (a) A1, (b) A2 and (c) A3 in Figure 15. 


\section{Discussion}

This study attempted to analyse the PS-InSAR derived long-term displacements by using time-series analysis. Firstly, during the PS-InSAR processing, we found that the VV polarisation is superior to the $\mathrm{VH}$ in terms of selecting more PS targets. However, the $\mathrm{VH}$ polarisation is more reliable than VV in suppressing the side lobe effect. As we know, in city areas, there may be many strong scatterers which shadow the adjacent targets. Whether this would affect the PS selection and the following processes should be further studied in the future.

Secondly, we derived a displacement map covering the HZMB and man-made islands. The results show that the main HZMB is quite stable, while the periphery of the IS2 is subsiding, and the IS3 is subsiding faster than the IS2 as larger subsiding rates of $13 \mathrm{~mm} /$ year and $17 \mathrm{~mm} /$ year are observed. The subsidence of the peripheral man-made islands like the P7 shown in Figure 9c may be caused by the twisted H-shaped concrete constructs attached to the islands to protect them from sea waves. The attachment and floating of the twisted H-shaped constructs are shown in Figure 17. These constructs could become heavier after a long time as they soak in sea water or are attached by marine organisms and microorganisms. On the other hand, the northern cloister of Zhuhai Passenger Terminal is also suffering a slighter subsidence of about $10 \mathrm{~mm} /$ year. Currently, we lack in-situ validation for these results.

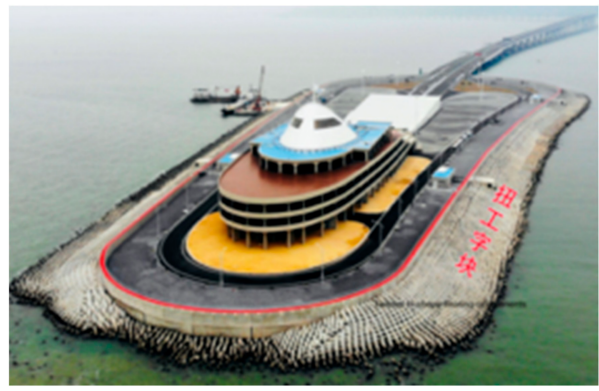

(a)

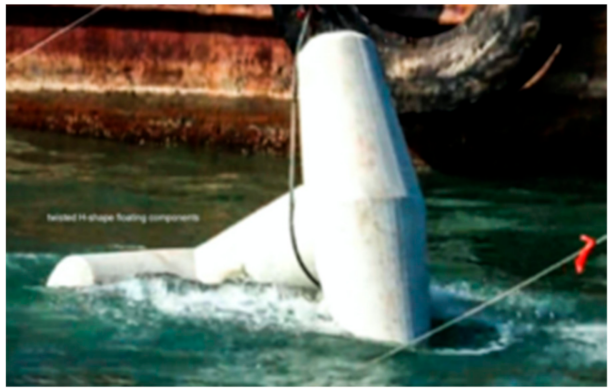

(b)

Figure 17. (a) Photo of the man-made island; (b) the twisted H-shape concrete constructs. (Photos from online resources).

The thermal expansion effect can be obviously observed in the temperature correlation map as shown in Figure 14. Different targets can react differently to the same temperature variation which has a period of one year. Figure $14 \mathrm{~b}$ shows the roof of the Zhuhai Passenger Terminal. The temperature correlation ranges from positive to negative at the near and far ranges. This can be explained by the horizontal expansion of the roof structure, which is similar to the thermal effect of the spans of bridges [21]. As shown in Figure 18a, when the temperature increases in the summer, the targets on the near range side move towards the satellite while those on the far range side move far away from the satellite. The same mechanism can be happening on the road and spans of bridges, as seen in Figure 18b. The road and the bridge span consist of concrete blocks, each of which has a horizontal expansion when the air temperature increases. High temperature correlation usually occurs at the edges of the block while low correlation occurs in the middle part. Heuristically, the correlation is obvious when the temperature correlation, $R$, is above 0.6 or below -0.6 . However, no obvious temperature correlation is observed on the main HZMB, and the reason is not yet found.

The ADF test is effective in picking out targets that contain an abrupt change in the InSAR-derived displacements. The higher the $p$-values, the more abnormity or larger changes reside in the time-series displacements excluding seasonal and trend components. Figure 16 shows three targets, A1-A3, with large $p$-values, $0.215,0.474$ and 0.786 , which indicate either abnormal uplifts or a sudden change between subsidence and uplift. In addition, the $p$-value for the P6 is 0.0020 , which may be associated with a sudden subsidence that occurred between early February and the end of July in 2019 on target P6, as seen in 
Figure 11b. It is 0.1455 for P7 and 0.015 for P8, which can be associated with a relatively large uplift that occurred on P7 and P8 between the middle of June and the middle of September in 2020, as shown in Figure 12. The period is coincident with the surge of precipitation in the rainfall season in 2020 as shown in Figure 6. However, it is hard to conclude a relationship between the uplifts and the precipitation due to a large distance of $26 \mathrm{~km}$ between the IS2 and the MIA. For P9, the $p$-value is 0.003 , which may be caused by the larger negative deviation of the displacements between April and June in 2018 as seen in Figure 13a.

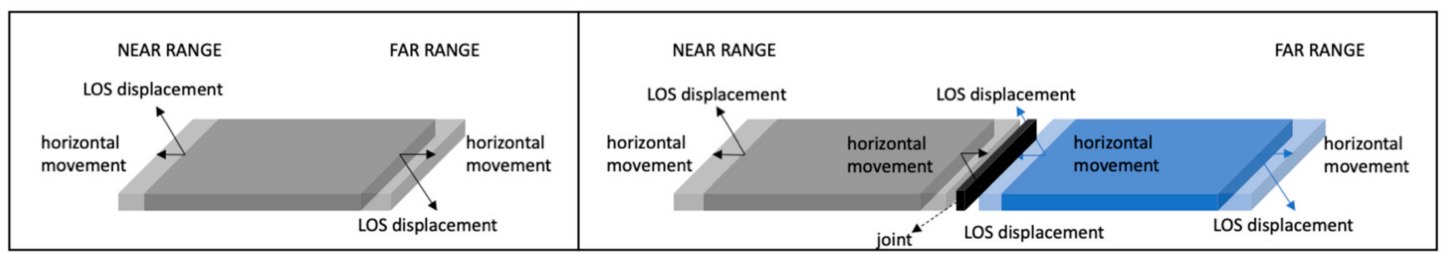

(a)

(b)

Figure 18. Sketches showing the mechanism of cyclic temperature correlation (a) on the roof of Zhuhai Passenger Terminal shown in Figure 14b and (b) bridges and roads shown in Figure 14c.

The proposed post-processing on the InSAR-derived displacements provides a useful tool to decompose linear, seasonal and non-linear changes quickly and efficiently. However, there are some shortages that have not been addressed in this study. For instance, only the seasonal component with a period of one year is considered with a priori knowledge of temperature change, but there may be other cyclic components. Taking P7 and P8 as examples, a half year cyclic change appears to be a likely situation. Moreover, this study uses temperature changes in 2018-2020 with the usage of two meteorologic stations. Obviously, this did not consider the spatial inhomogeneity of the temperature variation in the scene. Finally, although the ADF test can be used to detect targets suffering from abrupt changes, there is a need for a change point detection to reveal when these changes occur. This may be realised by automatic detection with the use of the piecewise linear model as proposed in [27].

\section{Conclusions}

This paper proposes the application of PS-InSAR and a post-processing analysis to the HZMB with the use of Sentinel-1A data from 6 January 2018 to 27 November 2020. Continuous subsidence of about $10 \mathrm{~mm}$ /year, $17 \mathrm{~mm}$ /year and $14 \mathrm{~mm} /$ year are revealed at the northern cloister of Zhuhai-Macao Passenger Terminal, the east man-made island and buildings on the Hong Kong Passenger Terminal, respectively. The periphery of the west man-made island has a slightly faster subsidence than the central part. Meanwhile, we demonstrated a temperature correlation map, which is produced by the post-processing based on EMD and STL. Periodic changes of the temperature correlation occur on the buildings, roads and bridges, influenced by the thermal expansion effect. Furthermore, the $\mathrm{p}$-value output from the ADF test was tested to be useful in detecting non-stationary signals remaining after removing linear and seasonal components.

Author Contributions: Conceptualization, S.X.; methodology, S.X.; software, S.X.; validation, X.Q.; formal analysis, S.X., C.W. and X.Q.; investigation, S.X. and C.W.; resources, S.X. and C.W.; data curation, S.X.; writing — original draft preparation, S.X.; writing - review and editing, S.X.; visualization, S.X. and B.Z.; supervision, Q.L.; project administration, S.X.; funding acquisition, S.X. All authors have read and agreed to the published version of the manuscript.

Funding: This research was primarily funded by China Postdoctoral Science Foundation (grant No. 2019M663073) and by the Shenzhen Scientific Research and Development Funding Programme (grant No. JCYJ20190808120005713). The authors are also grateful for the funding support from the Guangdong Basic and Applied Basic Research Regional Joint Foundation (grant No. 2019A1515111163), the National Natural Science Foundation of China (grant No. 41974006), Shenzhen Scientific 
Research and Development Funding Programmes (grant No. KQJSCX20180328093453763 and JCYJ20180305125101282) and the Department of Education of Guangdong Province (grant No. 2018KTSCX196).

Institutional Review Board Statement: Ethical review and approval were waived for this study, due to no involvement of humans and animals.

Informed Consent Statement: Not applicable.

Data Availability Statement: The Sentinel-1A dataset is publicly available via Alaska Satellite Facility (ASF, https:/ / search.asf.alaska.edu). The intermediate results and data generated during the study, i.e., displacement rate, temperature correlation, etc. can be accessed by requesting from the first author (xiongsiting@szu.edu.cn).

Acknowledgments: The authors would like to thank the ESA agency for releasing Sentinel-1A data to the public via the Copernicus programme, Alaska Satellite Facility (ASF) for providing data downloading API and the National Oceanic and Atmospheric Administration (NOAA) for releasing Global Surface Summary of the Day (GSOD) data to the public. The authors are also grateful to the China Postdoctoral Science Foundation and Shenzhen Science and Technology Innovation Commission for providing funding for the research.

Conflicts of Interest: The authors declare no conflict of interest. The funders had no role in the design of the study; in the collection, analyses, or interpretation of data; in the writing of the manuscript, or in the decision to publish the results.

\section{References}

1. The State-of-the-Practice of Modern Structural Health Monitoring for Bridges: A Comprehensive Review. Available online: http:/ / www.mtri.org/bridgecondition/doc/State-of-PracticeSHMforBridges(July2010).pdf (accessed on 3 February 2021).

2. Omar, T.; Nehdi, M.L. Remote sensing of concrete bridges decks using unmanned aerial vehicle infrared thermography. Automat. Constr. 2017, 83, 360-371. [CrossRef]

3. Liu, X.; Wang, P.; Lu, Z.; Gao, K.; Wang, H.; Jiao, C.; Zhang, X. Using terrestrial laser scanning (TLS), Ground-based microwave interferometry, and permanent scatterer interferometry synthetic aperture radar (PS-InSAR). Remote Sens. 2019, 11, 580. [CrossRef]

4. Alani, A.M.; Aboutalebi, M.; Kilic, G. Applications of ground penetrating radar (GPR) in bridge deck monitoring and assessment. J. Appl. Geophys. 2013, 97, 45-54. [CrossRef]

5. Meng, X.; Dodson, A.H.; Roberts, G.W. Detecting bridge dynamics with GPS and triaxial accelerometers. Eng. Struct. 2007, 29, 3178-3184. [CrossRef]

6. Zhang, B.C.; Ding, X.L.; Werner, C.L.; Tan, K.; Zhang, B.; Jiang, M.; Zhao, J.W.; Xu, Y.L. Dynamic Displacement Monitoring of Long-Span Bridges with a Microwave Radar Interferometer. Isprs J. Photogramm. Remote Sens. 2018, 138, 252-264. [CrossRef]

7. Lee, J.; Lee, K.C.; Lee, S.; Lee, Y.J.; Sim, S.H. Long-term displacement measurement of bridges using a LiDAR system. Struct. Control Health Monit. 2019, 26, 2428. [CrossRef]

8. Sousa, J.J.; Bastos, L. Multi-temporal SAR interferometry reveals acceleration of bridge sinking before collapse. Nat. Hazards Earth Syst. Sci. Discuss. 2013, 13, 659-667. [CrossRef]

9. Ferretti, A.; Prati, C.; Rocca, F. Nonlinear subsidence rate estimation using permanent scatterers in differential SAR interferometry. IEEE Trans. Geosci. Remote Sens. 2001, 38, 2202-2212. [CrossRef]

10. Ferretti, A.; Prati, C.; Rocca, F. Permanent scatterer in SAR interferometry. IEEE Trans. Geosci. Remote Sens. 2001, 39, 8-20. [CrossRef]

11. Berardino, P.; Fornaro, G.; Lanari, R.; Sansosti, E. A new algorithm for surface deformation monitoring based on small baseline differential SAR interferograms. IEEE Trans. Geosci. Remote Sens. 2002, 40, 2375-2384. [CrossRef]

12. Sousa, J.J.; Hlavacova, I.; Bakon, M.; Lazecky, M.; Patricio, G.; Guimaraes, P.; Ruiz, A.M.; Bastos, L.; Sousa, A.; Bento, R. Potential of Multi-Temporal InSAR Techniques for Bridges and Dams Monitoring. Procedia Technol. 2014, 16, 834-841. [CrossRef]

13. Milillo, P.; Giardina, G.; Perissin, D.; Milillo, G.; Coletta, A.; Terranova, C. Pre-collapse space geodetic observations of critical infrastructure: The Morandi Bridge, Genoa, Italy. Remote Sens. 2019, 11, 1403. [CrossRef]

14. Milillo, P.; Giardina, G.; DeJong, M.J.; Perissin, D.; Milillo, G. Multi-temporal InSAR structural damage assessment: The London Crossrail case study. Remote Sens. 2019, 10, 287. [CrossRef]

15. Owerko, T.; Kuras, P. Effective processing of radar data for bridge damage detection. Hindawi Shock Vib. 2019. [CrossRef]

16. Selvakumaran, S.; Plank, S.; Geiß, C.; Rossi, C.; Middleton, C. Remote monitoring to predict bridge scour failure using Interferometric synthetic aperture radar (InSAR) stacking techniques. Int. J. Appl. Earth Obs. Geoinf. 2018. [CrossRef]

17. Niu, F.; Liu, M.; Cheng, G.; Lin, Z.; Luo, J.; Yin, G. Long-term thermal regimes of the Qinghai-Tibet railway embankments in plateau permafrost regions. Sci. China Earth Sci. 2015, 58, 1669-1676. [CrossRef]

18. Ma, P.; Li, T.; Fang, C.; Lin, H. A tentative test for measuring the sub-millimeter settlement and uplift of a high-speed railway bridge using COSMO-SkyMed images. Isprs J. Photogramm. Remote Sens. 2019. [CrossRef] 
19. Qin, X.; Liao, M.; Zhang, L.; Yang, M. Structural health and stability assessment of high-speed railways via thermal dilation mapping with time-series InSAR analysis. IEEE J. Sel. Top. Appl. Earth Obs. Remote Sens. 2017, 10, 2999-3010. [CrossRef]

20. Qin, X.; Zhang, L.; Yang, M.; Luo, H.; Liao, M.; Ding, X. Mapping surface deformation and thermal dilation of arch bridges by structure-driven multi-temporal DInSAR analysis. Remote Sens. Environ. 2019. [CrossRef]

21. Zhang, L.; Sun, Q.; Hu, J. Potential of TCPInSAR in Monitoring Linear Infrastructure with a Small Dataset of SAR Images: Application of the Donghai Bridge, China. Appl. Sci. 2018, 8, 425. [CrossRef]

22. Wang, H.; Chang, L.; Markine, V. Structural health monitoring of railway transition zones using satellite radar data. Sensors 2019, 18, 413. [CrossRef] [PubMed]

23. Monserrat, O.; Crosetto, M.; Cuevas, M.; Crippa, B. The thermal expansion component of persistent scatterer interferometry observations. IEEE Geosci. Remote Sens. Lett. 2011, 8, 864-867. [CrossRef]

24. Chang, L. Monitoring Civil Infrastructure Using Satellite Radar Interferometry. Ph.D. Thesis, Delft University of Technology, Delft, The Netherlands, July 2015.

25. Wu, S.B.; Yang, Z.F.; Ding, X.L.; Zhang, B.C.; Zhang, L.; Lu, Z. Two Decades of Settlement of Hong Kong International Airport Measured with Multi-Temporal InSAR. Remote Sens. Environ. 2020. [CrossRef]

26. Lyu, M.; Ke, Y.; Li, X.; Zhu, L.; Guo, L.; Gong, H. Detection of seasonal deformation of highway overpasses using the PS-InSAR technique: A case study in Beijing urban area. Remote Sens. 2020, 12, 3071. [CrossRef]

27. Zhu, M.; Wan, X.; Fei, B.; Qiao, Z.; Ge, C.; Minati, F.; Vecchioli, F.; Li, J.; Costantini, M. Detection of building and infrastructure instabilities by automatic spatiotemporal analysis of satellite SAR interferometry measurements. Remote Sens. 2018, 10, 1816. [CrossRef]

28. Hu, Z.; Xie, Y.; Wang, J. Challenges and strategies involved in designing and constructing a $6 \mathrm{~km}$ immersed tunnel: A case study of the Hong Kong-Zhuhai-Macao Bridge. Tunn. Undergr. Space Technol. 2015, 50, 171-177. [CrossRef]

29. Gao, W.; Su, Q.; Zhang, J.; Xie, H.; Wen, F.; Li, F.; Liu, J. Steel Bridge Construction of Hong Kong-Zhuhai-Macao Bridge. Int. J. Steel Struct. 2020, 20, 1498-1508. [CrossRef]

30. Wegnüller, U.; Werner, C.; Strozzi, T.; Wiesmann, A.; Frey, O.; Santoro, M. Sentinel-1 support in the GAMMA software. Procedia Comput. Sci. 2016, 100, 1305-1312. [CrossRef]

31. Hooper, A.; Zebker, H.; Segall, P.; Kampes, B. A new method for measuring deformation on volcanoes and other natural terrains using InSAR persistent scatterers. Geophys. Res. Lett. 2004, 31, L23611. [CrossRef]

32. Huang, N.E.; Shen, Z.; Long, S.R.; Wu, M.C.; Shih, H.H.; Zheng, Q.; Yen, N.-C.; Tung, C.C.; Liu, H.H. The empirical mode decomposition and the Hilbert spectrum for nonlinear and non-stationary time series analysis. Proc. R. Soc. Lond. A 1998, 454, 903-995. [CrossRef]

33. Cleveland, R.B.; Cleveland, W.S.; McRae, J.E.; Terpenning, I. STL: A seasonal-trend decomposition. J. Off. Stat. 1990, 6, 3-73.

34. Global Surface Summary of the Day-GSOD, the National Oceanic and Atmospheric Administration (NOAA). Available online: https:/ / www.ncei.noaa.gov/metadata/geoportal/rest/metadata/item/gov.noaa.ncdc:C00516/html (accessed on 21 January 2021).

35. Fuller, W.A. Introduction to Statistical Time Series; John Wiley and Sons: New York, NY, USA, 1976; ISBN 0-471-28715-6.

36. Lopez, J.H. The power of the ADF test. Econ. Lett. 1997, 57, 5-10. [CrossRef] 